\title{
INTERNET ADDICTION AMONG YOUNG ADULTS AMIDST COVID 19 PANDEMIC
}

\author{
Yamuna G* \\ *Second year Bsc Psychology students, \\ Yuvakshetra Institute of Management Studies, \\ Mundur-2, Kerala, \\ India, 678631
}

\author{
Aswathy Venu KV* \\ * Second year Bsc Psychology students, \\ Yuvakshetra Institute of Management Studies, \\ Mundur-2, Kerala, \\ India, 678631
}

\author{
Sannet Thomas** \\ **Assistant Professor, \\ Yuvakshetra Institute of Management Studies , \\ Mundur-2, Kerala, \\ India, 678631
}

Article DOI: https://doi.org/10.36713/epra6557

\begin{abstract}
Internet addiction is a behavioral pattern characterized by excessive or obsessive use of online and offline computer, phone and other devices which has the ability to access internet. Coronavirus disease [covid 19] is an infectious disease caused by a newly discovered coronavirus [WHO]. The purpose of the study was to find the level of internet addiction among young adult during covid 19 pandemic. The study was conducted on 50 young adult out of which 25 were males and 25 were females with the age group of 18-25 through purposive sampling technique. Internet addiction test [young 1998] were used to collect data. Mean, SD, Independent sample T-test were used to analyse the data. The results shows that there is no significant difference in the level of internet addiction among the young adult across gender.
\end{abstract}

KEYWORDS: Internet addiction, COVID-19

\section{INTRODUCTION}

Internet addiction is behavioral pattern characterized by excessive or obsessive use of online and offline computer, phone and other devices which has the ability to access. Internet addiction is a worldwide problem among the millennials. Internet is a network that connects devices around the world. It is an integral part of people lives. Internet has many advantages like providing information, connecting people through social media, serving as an entertainment platform and so on. However with all the advantages internet has its own negatives. One of the major consequence of use of internet is Internet addiction, and most of the people with addictive behaviour do not even aware that they have addiction. It affect mental health and physical wellbeing badly

\section{Definition of key terms}

Internet addiction: Internet addiction is behavioral pattern characterized by excessive or obsessive use of online and offline computer, phone and other devices which has the ability to access internet.

\section{REVIW OF LITERATURE}

1. Menon, S., Narayanan, L., \& Kahwaji, A. (2018). conducted a study on internet addiction among 300 students to measure the level of addiction. Internet addiction scale(Young,1998) was used to collect data. ANOVA was used to analyze the data. The study has not found any severe addiction.

2. Anwar, E. (2014). conducted a study on internet addiction among secondary school children and its relation with their academic achievement. 300 secondary school students 
were participated in this study. Internet addiction scale(Young, 1998) was used to collect the data. $\mathrm{T}$ test was used to analyze the data. The study found that $10 \%$ of the students showed an extreme high level of addiction, and male students are more addicted to internet than female students.

3. Rajeswari, C., Ramachandra., Joseph, N., George, N., Pavithra,. K., Syhly, P., \& Jose, P.(2017). has conducted a study on internet addiction among the undergraduate students. The study consisted of 200 undergraduate students. The data was collected by Internet addiction test(Young,1998). The study has found that $1 \%$ of the students has severe addiction.

4. Prabhakaran, A,. M,C patel V.R, Ganjiwale, D., Nimbalkar , M.S (2016). conduct a study on Internet addiction and quality of life among young adults ,724 adolescents of vadodara, Internet addiction scale (young 1998) was used to collect data. In his survey he found that internet use for online friendship to be a significant predictor of IA and internet use for searching information was found to be protective against IA.

\section{Objective}

To study the level of internet addiction among young adults.

To study the level of internet addiction among young adults on the basis of gender

\section{Variables}

Independent variable: Gender

Dependent variable: Internet addiction

\section{Hypothesis}

There is no significant difference in the level of internet addiction among young adults across gender.

\section{Research design}

The study was in quantitative nature. The study adopted a between group design to determine any significance difference in the level of internet addiction among young adults during COVID 19 pandemic across gender.

\section{Research sample}

Purposive sampling method was used for the study. The sample included 50 young adults out of which 25 were females and 25 were males.

\section{Sampling criteria INCLUSION CRITERIA:}

1) Age limit: $18-25$

2) Those who have given consent to participate through online.

3) Participants from Kerala

\section{EXCLUSION CRITERIA}

1. Age group other than $18-25$

2. Those who have not given consent for participation

3. Those who have psychological problem

\section{Tool}

The following tool was used to gather the required data.

1) Internet Addiction Test(Young,1998)

\section{Procedure}

Purpose of the study was disclosed to the participants through online and their willingness to participate in the study was ascertained. The Internet Addiction Test(Young,1998) was given to the participants through online forms with proper instructions. The scoring of the evaluation was done and interpreted according to the manual.

\section{Analysis of data}

The collected data was analyzed using following statistical tools

1. Mean, Standard deviation

2. Independent sample t-test

\section{Ethical issue}

1. The collected data has been used only for research purpose.

2. Informed consent was taken from the participants.

\section{RESULTS}

\section{Data analysis and interpretation}

The purpose of the study was to study internet addiction among young adults during COVID 19 pandemic. The study consisted of 50 young adults out of which 25 were males and 25 were females. For the purpose investigator formulated a hypothesis and the results are shown below 
Figure 1:Subdivided bar diagram of internet addiction among young adults based on gender

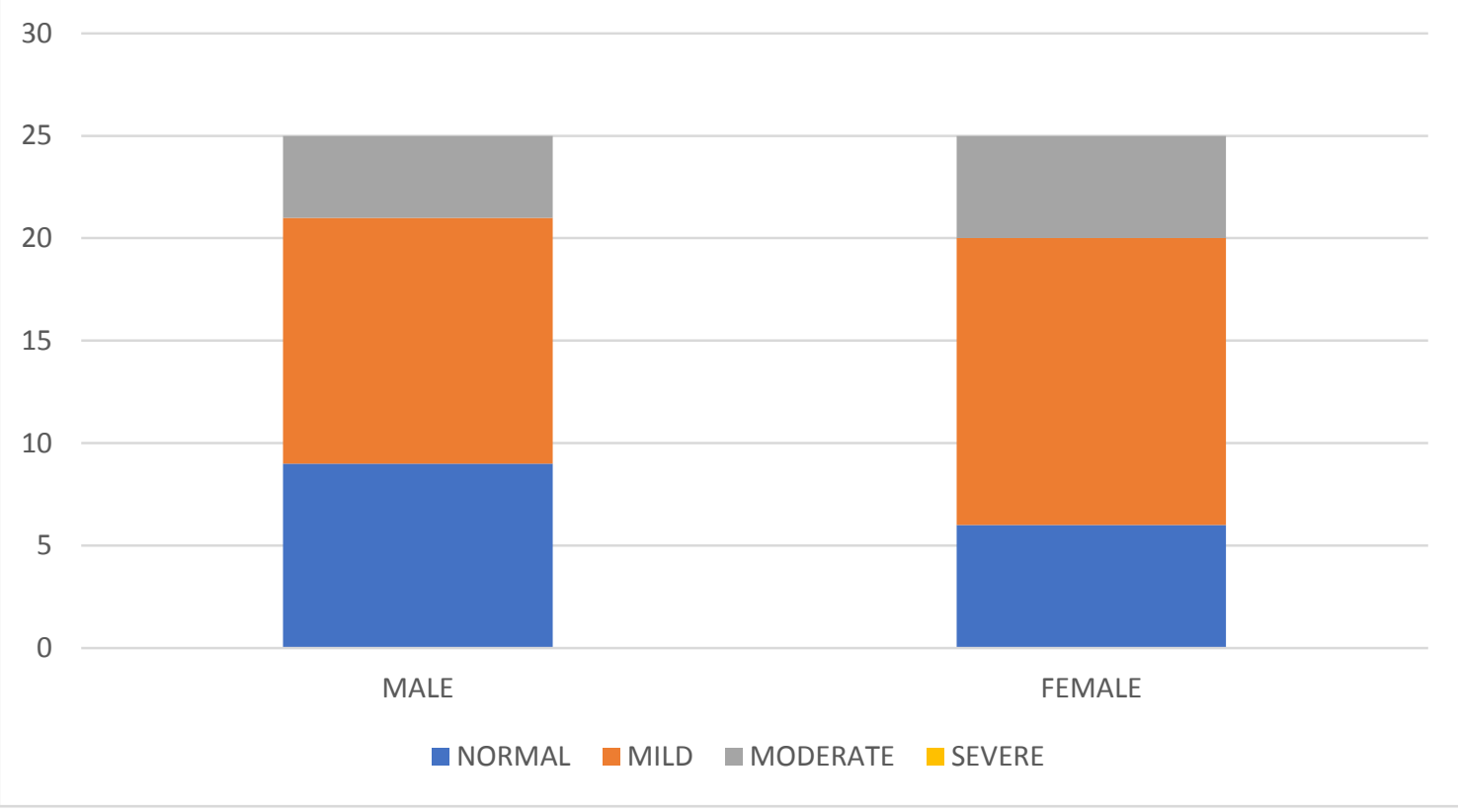

Table: 1 - Level of Internet addiction based on gender

\begin{tabular}{cccc}
\hline Level of addiction & Male & Female & Total \\
\hline Normal & 9 & 6 & 15 \\
Mild & 12 & 14 & 26 \\
Moderate & 4 & 5 & 9 \\
Extreme & 0 & 0 & 0 \\
\hline
\end{tabular}

Table 1: shows internet addiction among female and male young adults .Here 15 participants shows normal level of internet usage, 26 participants have mild internet addiction level, 9 participants have moderate dependency on internet and no participants shows severe dependency. It shows that number of males on normal level is higher than number of females, number of males on mild level is less than the number of females, number of males on moderate level is lower than the number of females in the same level of addiction, finally both the gender has not show any severe level of addiction.

Table 2.t value, Mean, SD, Sig value of Internet Addiction among young adults on gender

\begin{tabular}{ccccc}
\hline Gender & N & Mean & $\begin{array}{c}\text { Standard } \\
\text { Deviation }\end{array}$ & $\begin{array}{c}\text { Sig value(2- } \\
\text { tailed) }\end{array}$ \\
\hline Male & 25 & 35.4400 & 11.42030 & .851 \\
Female & 25 & 36.0400 & 10.99424 & .851 \\
\hline
\end{tabular}

Table. 2 shows that the average mean of males is 36.4400 and females is 36.0400 . The mean of females are slightly higher than of female. Significant value of level of internet addiction is 0.851 for both the gender which is not significant at the 0.05 level of significance. So the null hypothesis is accepted that there is no significant difference in the level of internet addiction among young adults across gender.

\section{MAJOR FINDING}

There is no significant level of difference in the level internet addition among young children across gender.

\section{Limitation}

Size of the sample was small.

Since the study was conducted in online mode the reliability of the participants answered the question cannot be verified.

\section{Implication}

The research can be used for benefits of people. The results show that the addiction level in female is higher than males, we can develop intervention programs for the female young adults with moderate addiction to reduce the level of addiction. 


\section{Scope}

It can be done in large population.

\section{REFERENCES}

1. Coronavirus.(2020). Retrieved 24 December 2020, from https://www.who.int/healthtopics/coronavirus

2. Menon, S., Narayanan, L., Kahwaji, A.T,(2018). Internet addiction: A research study of college students in India. Asian institute of research.

3. Anwar, E.(2014). Internet addiction among secondary school children and its relation with their academic achievement. PARIPEX-Indian journal of research.

4. Prabhakaran, A, M,C patel V.R , Ganjiwale, D., Nimbalkar, M.S (2016). factors associated with internet addiction among school going adolescents in vadodara.Rajeswari, C., Ramachandra., Joseph, N., George, N., Pavithra,. K., Syhly, P., Jose, P.(2017). Internet addiction among the undergraduate students. Nitte University Journal of Health Science.

5. Rajeswari, C., Ramachandra., Joseph, N., George, N., Pavithra,. K., Syhly, P., Jose, P.(2017). Internet addiction among the undergraduate students. Nitte University Journal of Health Science. 